\title{
The structural and technical solution for precipitation moisture reducing
}

\author{
Nazira Dzhumagulova ${ }^{1,2}$, Vladimir Smetanin ${ }^{2}$, and Nguyen Dinh Dap ${ }^{1, *}$ \\ ${ }^{1}$ Moscow State University of Civil Engineering, 129337, Yaroslavskoye Shosse 26, Moscow, Russia \\ ${ }^{2}$ Rusian State Agrarian University - Moscow Timiryazev Agricultural Academy, 127550, \\ Timiryazevskaya street 49, Moscow, Russia
}

\begin{abstract}
One of the main problems in Russia is an acute shortage of free land for the disposal of solid domestic waste and sewage sludge. The treatment and removal of precipitation is a major problem in wastewater treatment. Urban sewage treatment plants were built on model projects in the 1970s, in which natural dehydration on silt areas was provided. Sludge dehydration on silt areas of sewage treatment plants of medium and high capacity is impossible due to the lack of free land areas. The major drawback of this method is the rejection of significant land areas, contamination of the geo-environment, the release of pollutants into the air, as well as the loss of land resources. In sludge processing and utilization, it is necessary to achieve minimum damage to the environment and to increase the possibility of using it on behalf of the national economy. The adoption of new technology and processing of sediments allowed to reduce the initial amount of precipitation by 4 times and to reduce the humidity from $97 \%$ to $83 \%$, the amount of sludge formed at the treatment facilities will decrease by 6 times (from 300 $\mathrm{m}^{3} /$ day to $50 \mathrm{~m}^{3} /$ day) as a result of dehydration of the filter presses, the will be a reduction in the surface concentrations of pollutants in the atmosphere from 5,4 tons per year to 2,9 tons per year.
\end{abstract}

\section{Introduction}

Sewage sludge is unwanted residual solid wastes generated in wastewater treatment and its management is one of the most critical environmental issues of today. The treatment and disposal of sludge contribute a considerable proportion of the cost for running a wastewater treatment plant. The increasing amount of sewage sludge and more and more legislative regulation of its disposal have stimulated the need for developing new technologies to process sewage sludge efficiently and economically [1]. Within the European Union the total amount of produced sludge is about 6.5 million tons per year (Smith 1996). There are several disposal routes for sludge, including ocean dumping, incineration, spreading on agricultural land, soil incineration, land spreading in forestry or landfilling. At present the disposal of sludge on landfills is with $40 \%$ the most important outlet in the EU while $37 \%$ of the sewage sludge produced within the EU was used for agricultural purposes in 1994 (Hall 1994).

\footnotetext{
* Corresponding author : nguyendinhdap@gmail.com
} 


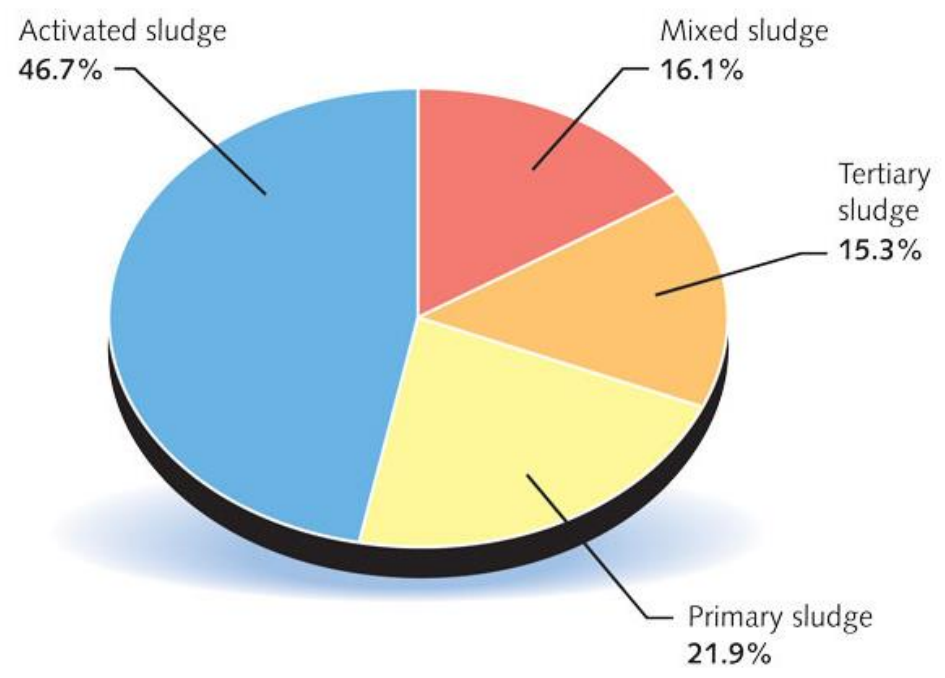

Fig. 1. Industrial sludge in Europe [2].

The amount of sewage sludge requiring disposal is expected to increase significantly in the future due to recent environmental developments. In addition to sewage sludge other wastes such as organic industrial wastes, manures, and organic household waste can with great advantage be recycled and used in farmland as fertilizers and as soil improving components [1]. Industrial sludge production is expected to increase between 2011 and 2017. As the volume of industrial sludge that requires treatment is growing, the amount of chemicals required for treatment will follow a similar increasing trend. In 2011, the European industrial sludge treatment chemicals market was worth $€ 785.8$ million presenting a moderate annual growth rate of $5.8 \%$ and a volume shipment of $1,309.7$ thousand tonnes [2].

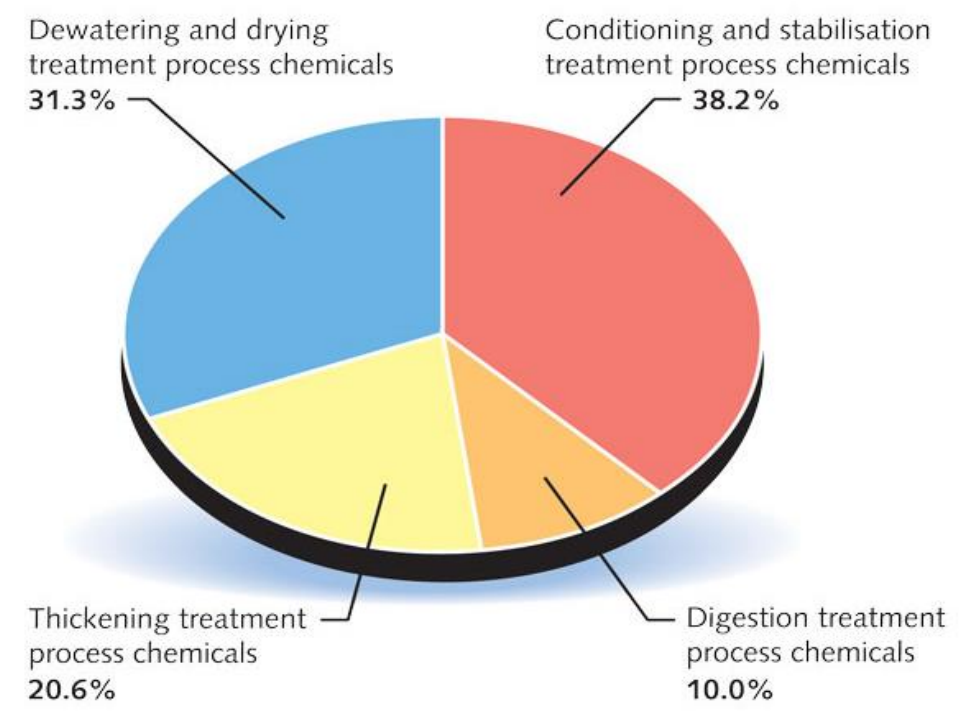

Fig. 2. Sluge p rocessing in Eupope [2].

However, this type of waste can contain possible hazardous components in small amounts, which might show adverse effects on the ecosystem, e.g. the farmland amended with sewage sludge [3]. 
In most European countries, no strict hygienic requirements are made for the reuse of sewage sludge in agriculture; most often there are only general requirements. Switzerland was the first European country to pass a sewage sludge Act, in 1981. This law requires disinfection of all sewage sludge that are reused on green land or fodder-plant areas. The law defines a sludge as disinfected if it has been treated especially for this purpose and contains, storage of sludge is required for at least three months before application $[4,5]$.

In the United States, sewage sludge resulting from municipal wastewater treatment must be treated in accord with federal and state requirements prior to being applied to land as a soil amendment, providing conditioning and fertilizing benefits. Such treated sludges are commonly referred to as biosolids. The most current data indicates that land application of biosolids is the most common use/disposal option for sewage sludge at $60 \%$ [1].

When choosing a rational technology for processing and utilization of sewage sludge, it is necessary to take into account the main economic and environmental factors: reduction of transport costs for removal of precipitation, reduction of areas needed for disposal, reduction of harmful emissions into the atmosphere. The treatment and removal of precipitation is a major problem in wastewater treatment [6]. Silt areas are widely used at urban sewage treatment plants for sludge dehydration. The major drawback of this method is the rejection of significant land areas, contamination of the geo-environment, the release of pollutants into the air, as well as the loss of land resources. In sludge processing and utilization, it is necessary to achieve minimum damage to the environment and to increase the possibility of using it on behalf of the national economy [7]. Technological schemes used to implement this task are very diverse [8].

In Russia, one of the primary tasks of the leadership of the sewage treatment plant in Chekhov city is the development of a technology that allows reducing areas used for sludge placing. Sewerage treatment facilities were built in 1976 with a design capacity of 50000 $\mathrm{m}^{3} /$ day. Currently, the actual volume of urban and industrial wastewater entering the treatment plant is about $25000 \mathrm{~m}^{3} /$ day [7].

In connection with the development of suburban land for housing construction, it is expected that population will continue to grow and the productivity of the sewerage plant will be increased up to the designed capacity. Accordingly, the growth of precipitation formation after wastewater treatment is expected. Purification of water at these facilities is carried out according to the classical scheme, which includes mechanical, biological treatment and post-cleaning. The sludge dehydration during the whole period of operation was carried out on seventeen cascade silt maps created on a natural basis. The total square of these treatment facilities is 13,45 ha or $134500 \mathrm{~m}^{2}$ and is determined by the volume of sludge discharges, as well as by the time of its natural drying to a state which is suitable for exporting by car to polygons [9].

\section{The problems and solutions}

In order to improve the environmental situation, to reduce humidity and precipitation volumes, mechanical sludge dehydration and its preparation for further use as organic fertilizers in green construction, afforestation, as well as for biological and technical reclamation of disturbed lands, etc, was designed.

Before the reconstruction of the silt detention ponds, processing sewage sludge is produced in the following way. Pumping methane tank is currently used as an intermediate pumping station for transfer to sludge drying beds of raw sludge and fatty film from the primary clarifiers and surplus biological sludge from the bio-coagulators.

The sludge utilization complex includes: pumping station methane tank, sludge drying beds of cascaded type and pumping station of sludge water. 
At sludge drying beds of cascaded type, there is a partial dehumidifying, preliminary drying and sludge digestion. During the natural process of digestion, there is the destruction of helminths and other microbes. Sludge drying beds consist of planned land plots (ponds) on the natural basis. Depth of the ponds is up to 2,5 m. In each cascade, there are 5-7 ponds. The number of beds is 17 .

Sludge water from all of the cascades is going to the gathering bed before the pumping station of sludge water. Then the water with pump through the drainage system is fed into the trough before the screen chamber. In the process of reconstruction of silt maps, it was decided to pre-dehydrate the sludge on the thickeners. As main equipment for sludge dehydration, belt filter presses LF-1500P were recommended in complex with belt thickeners. Such filter is designed for sludge dehydration of urban and industrial wastewater and pre-treated by reagents galvanic sludge dehydration.

Thus, after reconstruction of the silt detention ponds, technological scheme of processing sludge includes the following stages:

- feeding the raw sludge into the stabilization tank;

- uniform metered feeding the sludge to the extraction apparatus;

- preparing the work solution of the coagulant;

- conditioning the sludge with work solution of the coagulant;

- sludge thickening;

- accumulation of sludge drying in the sludge container.

Table 1. The main technical data and characteristics of the belt filter LF-1500S.

\begin{tabular}{|c|c|c|}
\hline \multicolumn{2}{|c|}{ Name of parameters } & Norm of filter \\
\hline \multicolumn{2}{|l|}{ Surface area of filtration, $\mathrm{m}^{2}$} & 3.5 \\
\hline \multirow{2}{*}{ Filter net width, m } & full & 1.5 \\
\hline & working & 1.3 \\
\hline \multicolumn{2}{|l|}{ The temperature of the slurry, $\mathrm{K}\left({ }^{\circ} \mathrm{C}\right)$} & $278-308(5-35)$ \\
\hline \multicolumn{2}{|c|}{$\begin{array}{l}\text { Productivity when initial concentrating in a suspension of a firm phase } \\
\text { up to } 5 \%, \mathrm{~m}^{3} / \text { hour, no more }\end{array}$} & 25 \\
\hline \multirow{2}{*}{ Power, kw } & thickener drive & 0.55 \\
\hline & compressor & 1.1 \\
\hline \multicolumn{2}{|c|}{ Characteristics of the electrical supply network } & $\begin{array}{l}\text { 3-phase, } 50 \mathrm{hz}, 380 \mathrm{v} \\
\text { with a deadly neutral }\end{array}$ \\
\hline \multirow{3}{*}{$\begin{array}{l}\text { Quantity and quality of washing water } \\
\text { suspended substances, } \mathrm{mg} / \mathrm{l}\end{array}$} & less & 6 \\
\hline & flow rate, $\mathrm{m}^{3} / \mathrm{h}$, more & 5 \\
\hline & Pressure, $\mathrm{MPa}$, more & 0.5 \\
\hline \multicolumn{2}{|c|}{ Material of main parts in contact with product } & $\begin{array}{l}\text { GOST } 380-84, \\
\text { polyurethane } \\
\text { composition }\end{array}$ \\
\hline \multirow{3}{*}{ Overall dimensions, $\mathrm{mm}$} & length & 3100 \\
\hline & width & 1920 \\
\hline & height & 1250 \\
\hline \multicolumn{2}{|l|}{ Mass, $\mathrm{kg}$} & 600 \\
\hline
\end{tabular}

In accordance with the technological scheme, the sludge and the condensed surplus biological sludge (hereinafter the sludge) are prepared in the existing methane tank of the second stage, which is used as the regulating stabilization tank. Feeding the raw sludge from the primary clarifiers and the condensed surplus biological sludge from bio-coagulators (structure in the form of a reservoir for intensification of the process of primary processing sewage water by preliminary coagulation of contaminants under conditions of artificial aeration and continuous mixing of sewage water with biological floc) of the second stage is carried out according to the existing scheme in the pumping station at the second stage methane tank. In the pumping station, the existing pumps FG-216-24 (2 pcs), with which the 
sludge is currently pumped on the silt detention ponds, are changed to new models CM 10065-250 a $\backslash 4$, with which the sludge will be fed to the methane tank to prepare a homogeneous mixture and further in the workshop of mechanical dehumidifying (WMD) in the receiving reservoir. Placement of equipment for mechanical dehumidifying of the sludge mixture is provided in the reconstructed existing building. The sludge from the storage tank is fed evenly to the belt thickener by screw-type sludge pumps and then to the filter press.

The technical data of the thickener must comply with the technical specifications (TU) and this technical description in accordance with table. 1.

\section{Results}

The filter consists of a horizontal frame - a prefabricated welded structure that is made of a barbed channel and coated by zinc (hot-dip galvanizing method). The filling table is a welded tray of thin gauge stainless steel. The filler tray is a $\Pi$-shaped box without a bottom, with seals on the contour that come into contact with the moving grid. The height of the duct as to the moving grid can be adjusted. Two filter grids are installed on the filter. Their stock is made according to the scheme attached to this TO (Fig. 3.).

One filtering grid (L1) slides on the casting table. On the casting table, a casting tray is installed, into which a mixture of sludge treated by a flocculant solution is fed. The initial sludge falls on the filtering grid - this is the zone of gravitational filtration. Then the sludge is transferred to another grid and wedge pressing begins - this is the moment of gradually increasing pressure on the sludge. Wedge is formed by two gradually converging grids. Further, filtering grids move together and the consecutive sludge pressing is carried out, first on the perforated drum, then on the squeeze rollers and at the end in the final (roller) pressing zone. The pressing roller assembly is a system of rollers of the same diameter. Next, in the sludge debarking zone, the filtering grids are separated and move separately. Dewatered sludge from filtering grids is removed by "floating" knives. Knife blades are made of vinyl plastic. The force of pressing the knives to the surface of the grids can be regulated by increasing or decreasing the rigidity (length) of the springs.

The filter is equipped with devices for optimal tension filter partitions, as well as their centering mechanisms, preventing their inadmissible displacement along the width of the filter. Each filtering partition is washed with water by means of its washing device. In the washer devices, nozzles are installed. Flushing fluid torches cover the entire surface of the rinsed grids. After washing, each grid falls on its centering roller.

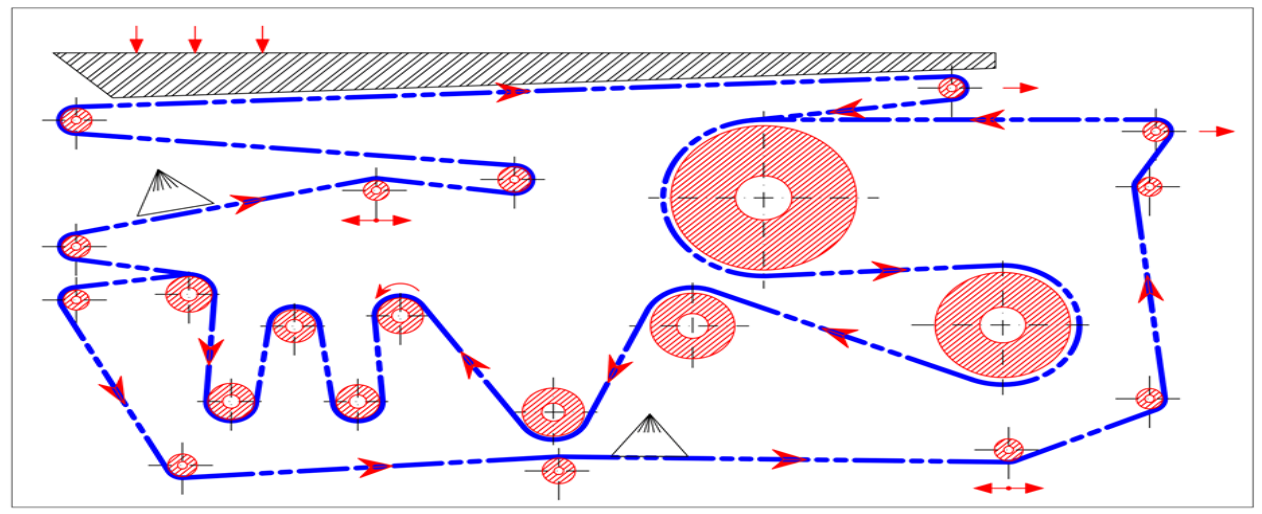

Fig. 3. Diagram of the movement of the filter belts. 
One side of the centering roller is fixed and has the ability to rotate, and the other side has the ability to move, which is carried out by an air cylinder. The dewatered sludge is transported to the storage area, in place of the existing maps (table 2), after their reconstruction. The total square of the silt maps is $15487 \mathrm{~m}^{2}$ (table 3).

The quantity and volume of sludge entering the treatment facilities are determined by the formulas:

$$
Q_{d r y}=\frac{C \cdot E \cdot K \cdot Q}{10^{6}}, \text { ton } / \text { day }
$$

where:

$\mathrm{Q}_{\text {dry }}$ - the amount of dry matter, ton/day;

$\mathrm{C}$ - initial concentration of suspended solids, $\mathrm{mg} / \mathrm{m}^{3}$;

E - effect of delaying suspended substances in primary sedimentation tanks in fractions of a unit is taken to be $0.5-0.6$;

$\mathrm{K}$ - coefficient that takes into account the increase in sludge volume due to large slurry fractions that are not captured when sample selecting for analysis, is taken to be 1.1 - 1.2,

$\mathrm{Q}$ - the inflow of sewage to the wastewater treatment plant, $\mathrm{m}^{3} /$ day [3].

From (1), $Q_{\text {dry }}=9000$ ton/day.

The amount of raw sludge formed in the treatment plants is determined by the formulas:

$$
V_{o c}=\frac{100 \cdot Q_{d r y}}{100-W_{o c}} \cdot P_{o c}, \mathrm{~m}^{3} / \mathrm{day}
$$

where:

$\mathrm{W}_{\mathrm{oc}}$ - the humidity of raw sludge, $\%$;

$\mathrm{P}_{\mathrm{oc}}$ - the density of raw sludge that is taken to be 1 .

From (2), the amount of raw sludge formed in the treatment plants is $300 \mathrm{~m}^{3} /$ day at a humidity of $97 \%$. The amount of sludge for dry matter $30 \mathrm{~kg} / \mathrm{m}^{3}$ :

$$
V_{o c}=\frac{100.900}{100-97} \cdot 1=300 \mathrm{~m}^{3} / \mathrm{day}
$$

The amount of the dewatered sludge at a humidity of $83 \%$ is determined by the formulas:

$$
V_{o c}=\frac{100.900}{100-83} \cdot 1=50 \mathrm{~m}^{3} / \text { day }
$$

Table 2. Characteristics of merged silt maps.

\begin{tabular}{|c|c|c|c|c|}
\hline \multicolumn{5}{|c|}{ Areas 2, 4, 6 before the merger } \\
\hline $\begin{array}{c}\text { Number of } \\
\text { silt areas }\end{array}$ & $\begin{array}{c}\text { Perimeter of } \\
\text { silt area, } \mathrm{m}\end{array}$ & $\begin{array}{c}\text { Square of silt } \\
\text { area }(S), \mathrm{m}^{2}\end{array}$ & $\begin{array}{c}\text { Filling height of silt } \\
\text { area }(h), \mathrm{m}\end{array}$ & $\begin{array}{c}\text { The volume of filling } \\
\text { of silt areas }(V), \mathrm{m}^{3}\end{array}$ \\
\hline 2 & 246 & 3128 & 2.3 & 7194.4 \\
\hline 4 & 273 & 4274 & 2.3 & 9830.2 \\
\hline 6 & 332 & 6535 & 2.3 & 15030.5 \\
\hline Total & 13397 & 2.3 & 32055 \\
\hline \multicolumn{5}{|c|}{ Areas $2,4,6$ after merger } \\
\hline $2,4,6$ & 542 & 16200 & 2.3 & 37260 \\
\hline
\end{tabular}

The volume of filing of silt areas is determined by the formulas:

$$
V=S . h, m^{3}
$$

where:

S - square of silt area, $\mathrm{m}^{2}$; 
$\mathrm{h}$ - filling height of silt area, $\mathrm{m}$.

From table 2 and formulas (5), the volume of filling of silt areas before the merger:

$$
V=S . h=13397 \times 2,3=32055 \mathrm{~m}^{3}
$$

And the volume of filling of silt areas after merger:

$$
V=S . h=13397 \times 2,3=32055 \mathrm{~m}^{3}
$$

The amount of sludge which placed on emergency silt maps is $22.000 \mathrm{~m}^{3}$ (table 3 ).

Table 3. Characteristics of emergency sludge maps

\begin{tabular}{|c|c|c|c|c|}
\hline \multicolumn{5}{|c|}{ Area 1, 3, 5, 7 } \\
\hline $\begin{array}{c}\text { Number of } \\
\text { silt areas }\end{array}$ & $\begin{array}{c}\text { Perimeter of } \\
\text { silt area, } \mathrm{m}\end{array}$ & $\begin{array}{c}\text { Square of silt } \\
\text { area }(S), \mathrm{m}^{2}\end{array}$ & $\begin{array}{c}\text { Filling height of silt } \\
\text { area }(h), \mathrm{m}\end{array}$ & $\begin{array}{c}\text { The volume of filling } \\
\text { of silt areas }(V), \mathrm{m}^{3}\end{array}$ \\
\hline 1 & 265 & 4046 & 1,38 & 5583 \\
\hline 3 & 255 & 3788 & 1,38 & 5227 \\
\hline 5 & 261 & 3830 & 1,38 & 5285 \\
\hline 7 & 268 & 4183 & 1,38 & 5772 \\
\hline Total & & 15847 & 1,38 & 22000 \\
\hline
\end{tabular}

From table 3 and formulas (5), the volume of filling of silt areas after the merger:

$$
V=S . h=15847 \times 1,38=22000 \mathrm{~m}^{3}
$$

Now let's consider the change of the parameters of atmospheric air under the influence of the projected object. The calculation of surface concentrations of pollutants in the atmosphere during the operation of the designed facilities is carried out in accordance with "Method for calculating the concentrations in the atmosphere of harmful substances contained in the industrial emissions" OND-86 under program "Ecology-PRO" version 3.0 in radius of $400 \mathrm{~m}$ in grid coordinates of $25 \mathrm{~m}$, with the company "Bifar".

Dispersion calculation is performed on one stage for the summer period, taking into account the background concentrations (table 4 and 5).

Table 4. Characteristics of silt maps before reconstruction

\begin{tabular}{|c|c|c|c|c|c|c|c|}
\hline Substances & $\begin{array}{c}\mathrm{U}, \\
\mathrm{m} / \mathrm{s}\end{array}$ & $\begin{array}{c}\mathrm{F} \\
\mathrm{m}^{2}\end{array}$ & $\begin{array}{c}\mathrm{F}_{\mathrm{o}} \\
\mathrm{m}^{2}\end{array}$ & $\begin{array}{c}\mathrm{C}_{\mathrm{i}} \\
\mathrm{mg} / \mathrm{m}^{3}\end{array}$ & $\begin{array}{c}\mathrm{m}_{\mathrm{i}} \\
\mathrm{g} / \mathrm{mole}\end{array}$ & $\begin{array}{c}\mathrm{M}_{\mathrm{i}} \\
\mathrm{g} / \mathrm{s}\end{array}$ & $\begin{array}{c}\mathrm{M}_{\mathrm{ic}} \\
\text { ton/year }\end{array}$ \\
\hline $\mathrm{H}_{2} \mathrm{~S}$ & 0,5 & 74386 & 74386 & 0,010000 & 34 & 0,003655 & 0,115269 \\
\hline $\mathrm{NH}_{3}$ & 0,5 & 74386 & 74386 & 0,100000 & 17 & 0,051692 & 1,630145 \\
\hline $\mathrm{C}_{2} \mathrm{H}_{5} \mathrm{SH}$ & 0,5 & 74386 & 74386 & 0,000013 & 62 & 3,520006 & 0,000111 \\
\hline $\mathrm{CH}_{3} \mathrm{SH}$ & 0,5 & 74386 & 74386 & 0,000027 & 48 & 8,310006 & 0,000262 \\
\hline $\mathrm{CO}_{2}$ & 0,5 & 74386 & 74386 & 0,060000 & 28 & 0,024167 & 0,762119 \\
\hline $\mathrm{N}_{2} \mathrm{O}$ & 0,5 & 74386 & 74386 & 0,038000 & 46 & 0,011941 & 0,376578 \\
\hline $\mathrm{CH}_{4}$ & 0,5 & 74386 & 74386 & 0,150000 & 16 & 0,079924 & 2,520472 \\
\hline Total & & & & & & 0,17139 & 5,404956 \\
\hline
\end{tabular}

Table 5. Characteristics of the silt maps after reconstruction

\begin{tabular}{|c|c|c|c|c|c|c|c|}
\hline Substances & $\begin{array}{c}\mathrm{U} \\
\mathrm{m} / \mathrm{s}\end{array}$ & $\begin{array}{c}\mathrm{F} \\
\mathrm{m}^{2}\end{array}$ & $\begin{array}{c}\mathrm{F}_{\mathrm{o}} \\
\mathrm{m}^{2}\end{array}$ & $\begin{array}{c}\mathrm{C}_{\mathrm{i}} \\
\mathrm{mg} / \mathrm{m}^{3}\end{array}$ & $\begin{array}{c}\mathrm{m}_{\mathrm{i}} \\
\mathrm{g} / \mathrm{mole}\end{array}$ & $\begin{array}{c}\mathrm{M}_{\mathrm{i}} \\
\mathrm{g} / \mathrm{s}\end{array}$ & $\begin{array}{c}\mathrm{M}_{\mathrm{ic}} \\
\text { ton/year }\end{array}$ \\
\hline $\mathrm{H}_{2} \mathrm{~S}$ & 05 & 40186 & 40186 & 0,010000 & 34 & 0,001975 & 0,062272 \\
\hline $\mathrm{NH}_{3}$ & 0,5 & 40186 & 40186 & 0,100000 & 17 & 0,027926 & 0,880663 \\
\hline $\mathrm{C}_{2} \mathrm{H}_{5} \mathrm{SH}$ & 0,5 & 40186 & 40186 & 0,000013 & 62 & 1,90006 & 5,990005 \\
\hline $\mathrm{CH}_{3} \mathrm{SH}$ & 0,5 & 40186 & 40186 & 0,000027 & 48 & 4,490006 & 0,000142 \\
\hline $\mathrm{CO}_{2}$ & 0,5 & 40186 & 40186 & 0,060000 & 28 & 0,013056 & 0,411724 \\
\hline $\mathrm{N}_{2} \mathrm{O}$ & 0,5 & 40186 & 40186 & 0,038000 & 46 & 0,006451 & 0,203441 \\
\hline $\mathrm{CH}_{4}$ & 0,5 & 40186 & 40186 & 0,150000 & 16 & 0,043178 & 1,36165 \\
\hline Total & & & & & & 0,092591 & 2,919952 \\
\hline
\end{tabular}


where:

$\mathrm{U}$ : wind speed, $\mathrm{m} / \mathrm{s}$;

F: surface area of a separate facility, $\mathrm{m}^{2}$;

$\mathrm{F}_{\mathrm{o}}$ : open surface area of a separate facility, $\mathrm{m}^{2}$;

$\mathrm{C}_{\mathrm{i}}$ : the concentration of the pollutant in the saturated vapor, $\mathrm{mg} \backslash \mathrm{m}^{3}$;

$\mathrm{m}_{\mathrm{i}}$ : the relative molecular mass of pollutants, $\mathrm{g} / \mathrm{mole}$;

Mi: the amount of a substances released per unit of time from a separate facility, $\mathrm{g} / \mathrm{s}$;

$\mathrm{M}_{\mathrm{ic}}$ : the total amount of substances released per year from an separate facility, ton/year.

In that way, the adoption of dehydration technology will allow fulfilling next environmental tasks:

- Reduction 4 times area for sludge storage (from $134500 \mathrm{~m}^{2}$ to $32047 \mathrm{~m}^{2}$ );

- The amount of sludge formed at the treatment facilities will decrease by 6 times (from $300 \mathrm{~m}^{3} /$ day to $50 \mathrm{~m}^{3} /$ day) as a result of dehydration of the filter presses;

- The maximum sludge dehydration from $97 \%$ to $83 \%$ will be ensured while maintaining the standard quality of discharged effluents;

- The will be a reduction in the surface concentrations of pollutants in the atmosphere from 5,4 tons per year to 2,9 tons per year.

\section{Conclusion}

The increasing amount of sewage sludge and more and more legislative regulation of its disposal have stimulated the need for developing new technologies to process sewage sludge efficiently and economically. When choosing a rational technology for processing and utilization of sewage sludge, it is necessary to take into account the main economic and environmental factors: reduction of transport costs for removal of precipitation, reduction of areas needed for disposal, reduction of harmful emissions into the atmosphere. The adoption of new technology and processing of sediments allowed to reduce the initial amount of precipitation by 4 times and to reduce the humidity from $97 \%$ to $83 \%$, the amount of sludge formed at the treatment facilities will decrease by 6 times (from $300 \mathrm{~m}^{3} /$ day to $50 \mathrm{~m}^{3} /$ day) as a result of dehydration of the filter presses, the will be a reduction in the surface concentrations of pollutants in the atmosphere from 5,4 to 2,9 tons per year.

\section{Reference}

1. J. Wang, Journal of Hazardous Materials, 143, 2-7 (2007)

2. Anna Jarosik, Water \& Water International, 1, 18-24 (2018)

3. Acquisto, A Bethany, S Robert S, Smith, E James, Pillai, D Suresh, Water Environment Federation, 61 to 70, 5345-5361 (2006)

4. Angelidaki I, Ahring B.K, Problems around sludge" (EDP Langenkamp and Marmo, 1999)

5. Lessel T, Sewage Sludge and Wastewater for Use in Agriculture (EDP Vienna1999)

6. Turovcky I, Sewage sludge processing. Treatment of Sewage Sludge. Dehydration and Disinfection (Deli print, 2008).

7. Technological regulations of treatment facilities of the municipal Enterprise of housing and communal services of Chekhov region (EDP Chekhov, 2009)

8. Sewage system. External networks and constructions (SNiP 2.04.03-85, 1986).

9. Dzumagulova N, Volshanik V, Golubka T, Theoretical and Applied Problems of Agroindustry, 2, 28-31 (2015) 